\title{
Effectiveness of Management Accounting System in Public Healthcare Sector: An Empirical Investigation in Vietnam
}

\author{
Quang-Huy, Ngo*
}

\begin{abstract}
Manuscript type: Research paper

Research aims: This paper aims to investigate the impact of decentralised structure on the effectiveness of management accounting system (MAS) in the Vietnamese public healthcare sector.

Design/Methodology/Approach: Data are collected from 165 public healthcare employees to test the proposed model. The PLS-SEM is used to assess the model. The common method bias is examined to ensure validity.

Research findings: Results show that the four characteristics of MAS - broad scope, timeliness, integration and aggregation mediate the relationship between decentralised structure and managerial performance.

Theoretical contribution/Originality: This study extends on previous studies looking at the use of MAS by focussing on the public healthcare entities of Vietnam. The study also shows that the four characteristics of MAS induce managerial performance. It therefore contributes to current knowledge by proposing the use of a framework to assess the cartesian contingency forms of fit. Finally, this study provides empirical evidence that highlights the use of accounting information for performance improvement.

Practitioner/Policy implication: This study offers information which strongly emphasises on the crucial role of the healthcare organisation structure, hence the outcome would be beneficial to practitioners.
\end{abstract}

\footnotetext{
* Quang-Huy, Ngo is a Vice-Dean at the Industrial Management Department, Can Tho University of Technology, 256 Nguyen Van Cu Street, Ninh Kieu District, Can Tho City, Vietnam. E-mail: nqhuy@ctuet.edu.vn
}

https:// doi.org/10.22452/ajba.vol13no2.6 
Research limitation/Implication: The limitation of this study lies in its instrument which lacked prior testing. The questionnaire administered was also self-rated, thus results may not be generalised.

Keywords: Decentralization, Healthcare Sectors, Management Accounting System, Managerial Performance, Public Sectors, Vietnam JEL Classification: M41, M1, I1

\section{Introduction}

The expansion of the healthcare industry has been drastic in the last decade or so, to the point that it could serve as the country's largest economic sector (Ditzel, Štrach \& Pirozek, 2006). The fast-growing pace of healthcare has also created many issues for organisations. One of these is the competition resulting from demographic changes as well as the emergence of new treatment and technology. These factors followed by the government's persistence force such organisations towards improving their service quality (see Westra, Angeli, Carree, \& Ruwaard, 2017).

The local government's explosive spending trends on other aspects (see Stadhouders, Koolman, Tanke, Maarse, \& Jeurissen, 2016) had been the cause for the lack of improvement in its healthcare sectors. This is because enhancing efficiency and improving service quality at the same time, requires funding. For healthcare organisations, effort is required to build and implement an effective management accounting system (MAS) (see Ramsey, 1994). There is some evidence from literature showing that healthcare organisations benefits from such systems. Macinati and Anessi-Pessina (2014), for instance, demonstrated that the use of management accounting information increases Italian hospitals' financial performance. Likewise, Pizzini (2006) noted that hospitals gained higher performance when they implemented the accounting information system which provided a more detailed cost information than their peers. Macinati and Rizzo (2014) also found a positive association between the use of accounting information as budget information and the budget performance of clinical managers who were attached to the public healthcare sectors. In a case study of a public hospital, Campanale, Cinquini and Tenucci (2014) observed that the accounting information generated by time-driven activity based costing enhanced the hospital's internal transparency and facilitated its decisionmaking with regards to resource allocations. 
The Vietnamese public healthcare sector, as an area less explored, offers a unique opportunity for research looking into the effectiveness of MAS within organisations. In recent years, the healthcare regulations of Vietnam had seen rapid changes (Pomberg, Pourjalali, Daniel, \& Kimbro, 2012). These changes had driven the public organisations into behaving differently from their counterparts in other countries, which are largely funded by the governments (Ramesh, 2013). Although MAS is an important system, to date, no study has been conducted to examine the impact of such changes on the effectiveness of MAS within healthcare organisations. Contingency theorists (Mia \& Chenhall, 1994; Soobaroyen \& Poorundersing, 2008) suggest that organisations should design MAS according to their contextual factors so as to foster the system's effectiveness.

Aiming to address the research gap, the current study thus focusses on the healthcare sector of Vietnam. In particular, it is deduced that the regulation change imposed on Vietnamese public healthcare forces organisations to be in line with the decentralised structure (London, 2013). Using the contingency theory as a framework, this paper thus proposes that the decentralised structure of organisations can influence the effectiveness of MAS, to the extent that it induces MAS to provide broad scope, timely, integrated, and aggregated information, thereby leading to higher managerial performances.

The remainder of this paper is structured as follows. Section 2 describes the theoretical background and hypotheses development. Section 3 presents the methodology. Section 4 focusses on the results and discussion while Section 5 concludes the paper by offering some practical implications.

\section{Literature Review and Hypotheses Development}

\subsection{The Background of Vietnamese Healthcare}

Before the implementation of the Doi Moi, an economic policy, the Vietnamese Ministry of Health had complete power over the Vietnamese healthcare system. After the implementation of the health regulations and reforms, the ministry's controlling power was subsequently reduced. The implementation of the health reforms thus generated three non-exclusive phrases (see Ramesh, 2013). The first of these was that public healthcare entities were permitted to charge users since government subsidies were reduced. Second, the government 
introduced health insurance which spread on a gradual basis as a means to offer the country's population with healthcare coverage as healthcare costs increased. Finally, the healthcare sector was decentralised as a system so as to improve the efficiency and accountability of public healthcare entities.

The implementation of these reforms had a dramatic impact on the operation of Vietnamese public healthcare entities. First, the competitive pressure increased dramatically as private healthcare providers also joined the market (Ramesh, 2013). Second, due to regulation changes, Vietnamese public healthcare entities came under the pressure to improve its efficiency as the government was gradually reducing its funding (London, 2013).

\subsection{The Role of MAS Design and its Effectiveness}

The literature of management accounting emphasises the crucial role of MAS in organisations. MAS refers to the systematic use of management accounting practices, which are designed to provide adequate information for decision-making so as to achieve organisational goals (Chenhall, 2003). Thus, the most important role of MAS is to provide useful information for decision-making.

The usefulness of the information depends on the degree of the MAS design which is represented by the four characteristics of: scope, timeliness, level of aggregation and integration (Chenhall \& Morris, 1986). As the first characteristic, scope covers dimensions, qualifications, and time horizons. Timeliness, as the second characteristic, refers to the speed of informational provisions. Aggregation is the third characteristic which includes categorising the information either by functional areas or time periods. Both are used in the formal decision model or the analytical model. The last characteristic describes the information, which helps the coordination of various segments within an organisation.

Previous studies (Soobaroyen \& Poorundersing, 2008) suggest that the effectiveness of the MAS design depends on the degree to which it effectively enhances managerial performance. The four characteristics of MAS had also been noted to impact managerial performance in several ways (Agbejule, 2005; Chong, 1998; Chong \& Chong, 1997). The effectiveness of the MAS design depends on whether or not it provides: broad scope, timely, integrated, and aggregated information, all of which allow users to improve their managerial performance. 


\subsection{The Impact of Contextual Factors on MAS Design}

Emmanuel, Otley and Merchant (1990) strongly affirmed that the MAS design depends on the contexts upon which organisations operate. Management accounting theorists (Chenhall, 2003) have proposed that one of the contextual factors affecting MAS design is decentralisation which has also been found to affect the healthcare sector (Hammad, Jusoh, \& Oon, 2010).

Decentralisation may possibly work for the Vietnamese public healthcare sector, claimed London (2013), who mentioned that healthcare organisations are under pressure to be more autonomous due to regulation changes. It is likely that such regulation and reforms have the means to shape the respective organisational structure to become more decentralised (Ramesh, 2013). As a result, decentralisation could thus influence the effectiveness of the MAS design. For that purpose, the current study has thus drawn a proposed research model which is illustrated in Figure 1.

\subsection{The Role of the Decentralised Structure on MAS Design}

Decentralisation is just one type of organisational structure. It refers to a system to which decision rights are delegated to the lower management level (Miah \& Mia, 1996). Thus, decentralised structure represents the

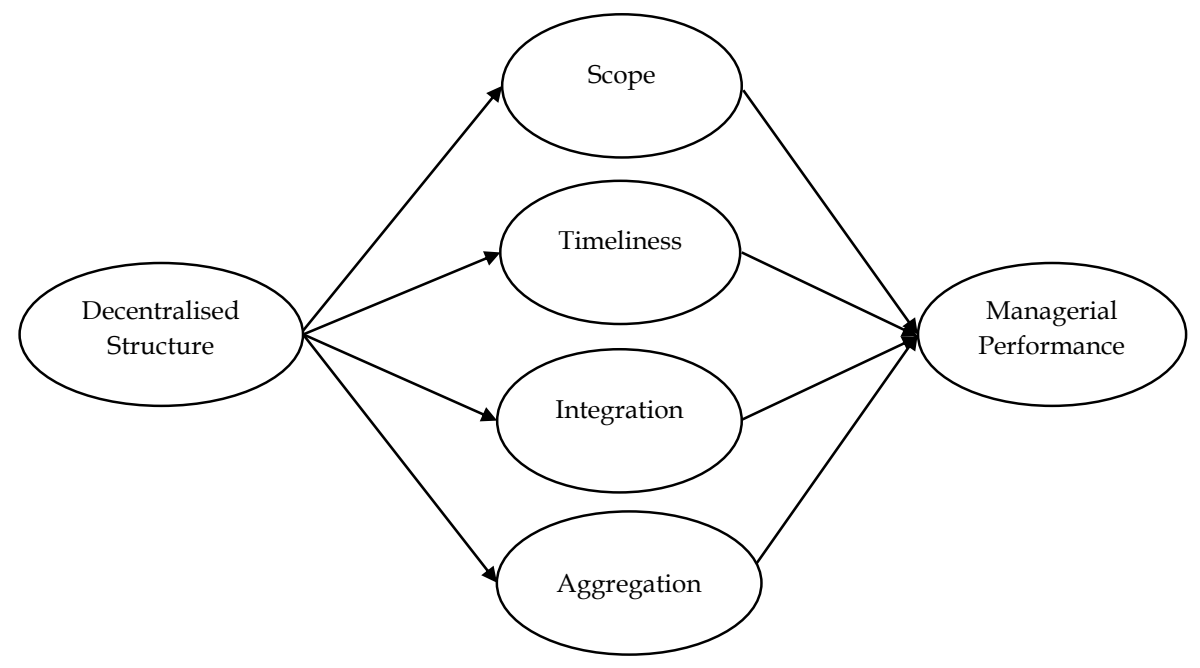

Figure 1: Research Model 
degree of autonomy provided by top managers to lower managers (Chia, 1995). This means that a high degree of decentralised structure provides more autonomy in the decision-making of lower management managers.

Management literature has many explanations outlining the relationship between decentralised structure and the informational demands of lower management levels. Thompson (1967) argued that organisations are more likely to follow the decentralised structure when faced with unpredictable environments. One explanation for this is that the increase in administrative complexity, tasks and responsibilities drive the top managers to delegate the decision rights to lower management as a means to ease their own burden of decision-making (Gordon \& Miller, 1976). In such conditions, lower management managers are thus expected to make, implement and be responsible for these decisions (Miah \& Mia, 1996). Consequently, the structural choices derived from the decision making thus influence the implication of the information system (Cushing \& Romney, 1994).

The decentralised structure may influence the MAS design used within organisations. This is because MAS has the vital role of providing useful information for decision-making. Such kind of structure is expected to impact the characteristics of the MAS design when used within such organisations. More specifically, a high degree of decentralisation requires that MAS be designed more sophisticatedly so as to provide a broader scope, timely, integrated and aggregated information that can be used by lower management managers in making good decision. Soobaroyen and Poorundersing (2008) found a positive correlation between decentralisation and the three characteristics of scope, timeliness and integration when examining the effectiveness of MAS design. In the same vein, this paper expects a positive relationship between decentralised structure and the sophistication of the MAS design. Based on this, the following hypotheses were formulated:

$\mathrm{H}_{1(\mathrm{a})}$ : A high degree of decentralised structure is positively associated with a high degree of broad scope information.

$\mathrm{H}_{1(\mathrm{~b})}$ : A high degree of decentralised structure is positively associated with a high degree of timely information.

$\mathrm{H}_{1(\mathrm{c})}$ : A high degree of decentralised structure is positively associated with a high degree of integrated information.

$\mathrm{H}_{1(\mathrm{~d})}$ : A high degree of decentralised structure is positively associated with a high degree of aggregated information. 


\subsection{The Role of MAS Design on Managerial Performance}

The MAS literature specifies the impact of MAS design on managerial performance. It was suggested that managers were constantly required to make decisions to solve problems and issues related to their areas of responsibility. In order to improve the effectiveness of the decisionmaking process, managers search for information which can be used to evaluate their current situations, to consider alternatives, make choices, and also to take actions. MAS plays a crucial role in this process because its main role is to provide information for managers to make decisions effectively (Ghasemi, Mohamad, Karami, Bajuri \& Asgharizade, 2016). A proper design of this system allows managers to make effective decisions, hence leading to higher performance (Chenhall, 2003). Based on this, it is possible to argue that the design of MAS influences managerial performance.

The impact the MAS design has on managerial performance has been intensively examined. Specifically, Ghasemi et al. (2016) found that three characteristics of the MAS design encompassing scope, timeliness and aggregation, had a positive association with managerial performance. Soobaroyen and Poorundersing (2008) indicated that broad scope, timely, integrated and aggregated MAS information leads to higher managerial performance. Likewise, Etemadi, Dilami, Bazaz and Parameswaran (2009) also revealed that the performance of Iranian managers was high when MAS provided the broad scope and timely information properly. Chong (1998), and Chong and Eggleton (2003) demonstrated that a broad scope of information, and the high use of this information is positively associated with managerial performance. Based on this, it is deduced that a more sophisticated MAS design effectively fosters managerial performance.

In the healthcare context, MAS information also plays a crucial role in improving the quality of healthcare users' decisions. For instance, Hill (2000) argued that less detailed information provided by MAS could lead to poor quality decision-making, and this in turn, caused a decrease in quality and low net income. Pizzini (2006) also stated that detailed MAS information can positively improve hospitals' operational profit. It was argued that the degree of healthcare users using information for improvement lies in the quality of the MAS design (Macinati \& AnessiPessina, 2014). As such, a more sophisticated MAS design is expected to provide broad scope, timely, integrated and aggregated information. This would, in turn, allow healthcare managers to perform better (see 
Hammad, Jusoh \& Ghozali, 2013; Hammad et al., 2010). Based on this, the following hypotheses were formulated:

$\mathrm{H}_{2(\mathrm{a})}$ : A high degree of broad scope MAS information is passively associated with a high degree of managerial performance.

$\mathrm{H}_{2(\mathrm{~b})}$ : A high degree of timely MAS information is passively associated with a high degree of managerial performance.

$\mathrm{H}_{2(\mathrm{c})}$ : A high degree of integrated MAS information is passively associated with a high degree of managerial performance.

$\mathrm{H}_{2(\mathrm{~d})}$ : A high degree of aggregated MAS information is passively associated with a high degree of managerial performance.

\subsection{The Mediating Effects of MAS Design on the Relationship between Decentralised Structure and Managerial Performance}

Organisational structure is a mechanism underlining the operations of the functional departments or sub-units. The vital role of organisational structure on departmental performance has been highlighted by Van den Ven (1976). It was further suggested that the relationship between organisational structure and performance was the most vexing and ambiguous in management and organisational behaviour literature (Dalton, Todor, Spendolini, Fielding, \& Porter, 1980). The MAS literature has adequate evidence supporting that the impact of organisational structure on performance would depend on the fit of the MAS design and the kind of organisational structure available (Chong, 1998; Gerdin, 2005; Gerdin \& Greve, 2004; Mak, 1989).

Gerdin and Greve (2004) provided some crucial suggestions for modelling the form of fit between the contextual factors, and the sophistication of the MAS design. In particular, the forms of the fit can be assessed by cartesian or configuration approaches. Since the present study is examining single contextual factors, the cartesian approach was applied. In this approach, only one model (e.g. moderation or mediation) can be applied to a single situation. Since the first hypothesis indicates the positive relationship between decentralised structure and the sophistication of the MAS design, the use of the mediating model seemed adequate. The mediating model is appropriate for contingency and congruence approaches. As the dependent variable of this study is managerial performance, the contingency approach was thus deemed suitable for explaining the mediating effects. The mediating effects of the 
MAS design derived from the current study were more likely to follow the contingency approach in the cartesian form.

Previous research (Ghasemi et al., 2016; Ghasemi, Habibi, Ghasemlo \& Karami, 2019; Ismail \& Isa, 2011) provides evidence showing the mediating effects of MAS design on the association between single contextual factors and performance. Ghasemi et al. (2016) noted the mediation effects of MAS design on the relationship between competition and performance while Ghasemi et al. (2019) revealed that MAS design mediated the links between technology and managerial performance. Similarly, Ismail and Isa (2011) confirmed that the relationship between advanced manufacturing technology and performance was mediated by broad scope MAS information. Likewise, this paper anticipates the mediating impact of the MAS design on the link between decentralised structure and managerial performance. Thus, the following hypotheses were formulated:

$\mathrm{H}_{3(\mathrm{a})}$ : Broad scope MAS information mediates the relationship between decentralised structure and managerial performance.

$\mathrm{H}_{3(\mathrm{~b})}$ : Timely MAS information mediates the relationship between decentralised structure and managerial performance.

$\mathrm{H}_{3(\mathrm{c})}$ : Integrated MAS information mediates the relationship between decentralised structure and managerial performance.

$\mathrm{H}_{3(\mathrm{~d})}$ : Aggregated MAS information mediates the relationship between decentralised structure and managerial performance.

\section{Method}

\subsection{Data Collection}

A survey was administered on the healthcare organisations located in Can Tho city, one of the biggest city in the south of Vietnam. Le, Kubo, Fujino, Pham and Matsuda (2010) had suggested that the Vietnamese healthcare system consists of four levels - central, provincial, district and commune. In this regard, the questionnaires were thus sent to managers working in the provincial hospitals, district general hospital, and healthcare centres for prevention in Can Tho city.

Because all the measures used in this study are in English, a translation to Vietnamese was made. During the translating process, two chief accountants were asked to examine the relevance of the statements in the Vietnamese public healthcare organisations. They are working 
in the public healthcare organisations located in Can Tho city. Some modifications were made before sending out to the target respondents. This study takes advantage of the personal networking link to collect data, hence convenience sampling was applied. In particular, a student from a Master's accounting class agreed to assist the collection process. This person has a strong relationship with the health department of Can Tho city. The collection process involved three steps. First, an email introducing the purpose of the study, and the link to access the online survey, was sent to the respective health department. Second, the department helped to forward this email to all healthcare entities located in Can Tho city. A total of fifteen public hospitals and twelve public healthcare centres located in this city were involved. Similar to Hammad et al. (2013) and Radford, Pink, Ricketts and Spade (2007), the target respondents were those in charge of the managerial position in the healthcare entities. In the survey, a question, which forces the respondents to indicate whether or not they were in charge of any managerial position, was added to ensure that the target respondents were recruited. Lastly, when the email reached the respective healthcare entities, the same email was disseminated to the target respondents' personal email addresses. Therefore, the target respondents were all voluntary participants. This study also emphasised on the anonymity of the respondents by removing questions related to their personal information (e.g. name, ages, gender). In total, 165 questionnaires were collected and used for analysis.

\subsection{Measures}

\subsubsection{Decentralised Structure (STR)}

The decentralised structure represents the degree of autonomy upon which top managers provide to lower management managers. Therefore, an instrument adapted from the study of Abernethy and Lillis (2001) was implemented. Some minor wording adjustments were made to make the statements clearer and more comprehensible. In this measure, respondents were asked to indicate their responses based on the following statements: (1) Clinical units are responsible for costs incurred in their units; (2) Clinical units are responsible for managing throughput in their units; (3) Clinical units are considered as a business unit, which is responsible for both costs and revenues; (4) Our organisation has a contract, which constrains the clinical unit managers 
to be accountable for both costs and throughput targets. The instrument implemented was considered reliable because it had been implemented by previous management accounting studies in the healthcare context (Abernethy \& Lillis, 2001; Hammad et al., 2013). This instrument used the 5-point Likert scale ranging from (1) highly disagree to (5) highly agree for responses.

\subsubsection{Sophistication of MAS Design}

The instruments from Chenhall and Morris (1986) were adapted to measure the four characteristics of the MAS design (see Table 1). This instruments had been intensively used in previous MAS studies in hospitals (Hammad et al., 2013), financial institutes (Ghasemi et al., 2016), and manufacturing companies (Soobaroyen \& Poorundersing, 2008). Hence, they offer a high reliability. This instruments were also measured by the 5-point Likert scale ranging from (1) highly disagree to (5) highly agree.

\subsubsection{Managerial Performance (PER)}

This study applies the instruments taken from Mahoney (1963) as they have high reliability since they have been widely used in management accounting studies (Agbejule, 2005; Chia, 1995; Chong \& Eggleton, 2003; Ghasemi et al., 2016; Gul \& Chia, 1994; Nguyen, Mia, Winata \& Chong, 2017; Tsui, 2001). The instruments ask respondents to rate their performance based on the following nine activities: (1) planning, (2) investigating, (3) coordinating, (4) evaluating, (5) supervising, (6) staffing, (7) negotiating, (8) representing and (9) overall performance. The 5-point Likert scale ranging from (1) well below average to (5) well above average, was used to measure the responses.

\subsection{Assessment of Data Normality}

Ali, Rasoolimanesh, Sarstedt, Ringle and Ryu (2018) suggested that the normality of data should be taken be into consideration before testing the model. Hence, the Kolmogorov-Smirnov test and the Shapiro-Wilk test were assessed. The results revealed a significant deviation from normality. Thus, the partial least square structural equation modelling (PLS-SEM) was applied since it is capable of handling non-normality data, and a small sample size (Cassel, Hackl \& Westlund, 1999; Hair, Hult, Ringle, Sarstedt \& Thiele, 2017). 
Table 1: Instruments Measuring the Sophistication of MAS Design

Scope (SCO)

Information that relates to possible future events.

Quantification of the likelihood of future events occurring.

Non-economic information.

Information on broad factors external to your organisation.

Non-financial information that relates to the efficiency, output rates, employee absenteeism, etc.

Timeliness (TIM)

Requested information to arrive immediately upon request.

Information supplied to you automatically upon its receipt into information systems or as soon as processing is completed.

Reports are provided frequently on a systematic, regular basis.

There is no delay between event occurring and relevant information being reported to you.

Aggregation (AGG)

Information provided on the different sections or functional areas in your organisation.

Information on the effect of events on particular time periods.

Information that has been processed to show the influence of events on different functions.

Information on the effect of different sections' activities on summary reports for your department and the overall organisation.

Information in forms that enable you to conduct "what-if" analysis.

Information in format suitable for input into decision models.

Costs separated into fixed and variable components.

Integration (INT)

Information on the impact that your decision will have throughout your department, and the influence of other individuals' decisions on your area of responsibility. Information on precise targets for the activities of all sections within your department.

Information that relates to the impact that your decisions have on the performance of your department. 


\subsection{Assessment of Common Method Bias}

Because all the measures were collected from the same survey, it may create an issue of common method bias. This was henceforth assessed through two tests. First, Harman's single-factor test (Podsakoff \& Organ, 1986) was applied. This test assumes that if a substantial amount of a common method variance exists, a factor analysis of all measures would result in a single factor, thereby accounting for the covariance among the measures. In this context, the Principal Axis Factoring analysis was performed on the items by measuring all the constructs (STR, SCO, TIM, INT, AGG, PER). Results ${ }^{1}$ revealed that no single factor accounted for the majority of the variance in the measures.

The second test was assessed using the marker variable (Lindell \& Whitney, 2001). A marker variable, which theoretically has no relationship with the main variable, is necessary so as to examine the common method bias. If the correlation test between these variables reveal no relationship, then common method bias does not exist. In this study, the marker variable (MKR) assessed the respondents' perception of travel-

Table 2: Pearson Correlation between Latent Variables

\begin{tabular}{llccccccc}
\hline & & AGG & INT & MKR & PER & SCO & STR & TIM \\
\hline AGG & Correlation & & & & & & \\
& $p$-value & & & & & & \\
INT & Correlation & $0.421^{* *}$ & & & & & \\
& $p$-value & 0.000 & & & & & & \\
MKR & Correlation & -0.017 & 0.050 & & & & & \\
& $p$-value & 0.825 & 0.522 & & & & \\
PER & Correlation & $0.295^{* *}$ & $0.350^{* *}$ & -0.038 & & & \\
& $p$-value & 0.000 & 0.000 & 0.625 & & & \\
SCO & Correlation & -0.014 & 0.027 & -0.020 & $0.360^{* *}$ & & \\
& $p$-value & 0.855 & 0.732 & 0.803 & 0.000 & & \\
STR & Correlation & $0.335^{* *}$ & $0.289^{* *}$ & 0.060 & $0.169^{*}$ & $0.247^{* *}$ & & \\
& $p$-value & 0.000 & 0.000 & 0.442 & 0.030 & 0.001 & \\
TIM & Correlation & -0.008 & 0.039 & 0.022 & $0.347^{* *}$ & $0.453^{* *}$ & $0.224^{* *}$ \\
& $p$-value & 0.916 & 0.620 & 0.782 & 0.000 & 0.000 & 0.004 & \\
\hline
\end{tabular}

Note: ${ }^{* *}$ Correlation is significant at the 0.01 level (2-tailed), * correlation is significant at the 0.05 level (2-tailed).

1 The total variance explained by one single factor was $22.754 \%$ which is less than the threshold value of $50 \%$. 
ling. In particular, the instrument measuring this variable consists of four items: (1) Travelling helps people to learn more about local culture; (2) Travelling helps people to reduce stress; (3) Frequent travelling is necessary; (4) Overall, travelling is good. Table 2 displays the outcome showing that this marker variable has no relationship with other main variables. Thus, common method bias is not a concern of this study.

\section{Results}

\subsection{Descriptive Statistics}

Table 3 shows the characteristics of the respondents and healthcare organisations. Panel A illustrates that majority of the respondents had a bachelor's degree while respondents with a professional diploma, associate degree, and masters contributed to 4.24 per cent, 5.45 per cent, and 2.42 per cent, respectively. The outcome also showed that lower management managers comprised 45.45 per cent while middle and top managers comprised 30.91 per cent and 0.90 per cent respectively. Panel A also shows that most respondents have 1-5 years' experience while 1.82 per cent of them had been working for 15-20 years.

Panel B illustrates the respondents' background. Majority of them worked in hospitals. Most of them worked in organisations with less than 150 employees. Although a minority of the respondents worked at healthcare centres, they were not included for further analysis. This is because managers working at healthcare centres were familiar with the use of accounting information which can be used to improve their work performance (see Radford et al., 2007).

\subsection{Hypothesis Testing}

This study employed the SmartPLS version 3.2.7, a PLS-SEM tool to test the proposed model. We evaluated the psychometric properties of the measurement model first, and then estimated the parameters of the structural model.

\subsubsection{Evaluating the Validity of the Measurement Model}

This study followed two steps in evaluating the measurement model. The first step analyses the unidimensionality of all the constructs by using the conduction of the principal axis factoring with Oblimin rotation (see Fabrigar, Wegener, MacCallum, \& Strahan, 1999). The results 
Table 3: Descriptive Statistics of Respondents and Healthcare Organisations

\begin{tabular}{lrr}
\hline Panel A: Respondents' characteristics & Frequency & $\%$ \\
\hline Education & 7 & 4.24 \\
Professional diploma & 9 & 5.45 \\
Associate degree & 145 & 87.88 \\
Bachelor & 4 & 2.42 \\
Master & & \\
Professional level & 75 & 45.45 \\
Lower-management level & 51 & 30.91 \\
Middle management level & 15 & 9.09 \\
Top management level & 24 & 14.55 \\
Not specified & & \\
Experience at the current position & 4 & 2.42 \\
Less than 1 year & 70 & 42.42 \\
1-5 year & 59 & 35.76 \\
6-10 year & 29 & 17.58 \\
11-15 year & 3 & 1.82 \\
15-20 year & &
\end{tabular}

Panel B: Working environment characteristics

Type

Hospitals 144

87.27

Healthcare centres

Number of employees

$<150$

$150-250$

250-350

showed six extracted components which corresponded to the number of intended constructs, except for three items, such as AGG_3, AGG_6, and STR_4. These items had to be removed because their loadings were below 0.5 (Hair, Anderson, Babin, \& Black, 2010).

After the removal of these items, the same conduction was repeated so as to allow a rigorous assessment of the construct dimensionality (Rook \& Fisher, 1995). In total, six extracted components corresponded 
Table 4: Cross-loadings and VIFs

\begin{tabular}{lrrrrrrr}
\hline & AGG & INT & PER & SCO & STR & TIM & VIF \\
\hline AGG_1 & $\mathbf{0 . 8 8 3}$ & 0.331 & 0.202 & -0.064 & 0.244 & -0.090 & 3.358 \\
AGG_2 & $\mathbf{0 . 8 1 9}$ & 0.358 & 0.237 & -0.063 & 0.220 & -0.062 & 2.165 \\
AGG_4 & $\mathbf{0 . 8 9 9}$ & 0.391 & 0.302 & -0.008 & 0.298 & 0.015 & 3.287 \\
AGG_5 & $\mathbf{0 . 9 0 4}$ & 0.393 & 0.280 & 0.007 & 0.282 & 0.007 & 3.459 \\
AGG_7 & $\mathbf{0 . 8 0 3}$ & 0.332 & 0.233 & 0.047 & 0.305 & 0.070 & 1.905 \\
INT_1 & 0.385 & $\mathbf{0 . 8 8 6}$ & 0.317 & 0.004 & 0.267 & 0.019 & 1.876 \\
INT_2 & 0.357 & $\mathbf{0 . 8 3 5}$ & 0.298 & 0.022 & 0.234 & 0.111 & 1.604 \\
INT_3 & 0.302 & $\mathbf{0 . 7 7 7}$ & 0.254 & 0.047 & 0.156 & -0.052 & 1.546 \\
PER_1 & 0.219 & 0.316 & $\mathbf{0 . 8 4 1}$ & 0.296 & 0.160 & 0.315 & 2.799 \\
PER_2 & 0.280 & 0.326 & $\mathbf{0 . 8 2 5}$ & 0.308 & 0.157 & 0.352 & 2.513 \\
PER_3 & 0.267 & 0.239 & $\mathbf{0 . 8 3 8}$ & 0.328 & 0.135 & 0.264 & 2.756 \\
PER_4 & 0.263 & 0.291 & $\mathbf{0 . 8 2 4}$ & 0.336 & 0.104 & 0.302 & 2.593 \\
PER_5 & 0.237 & 0.282 & $\mathbf{0 . 8 1 1}$ & 0.230 & 0.061 & 0.231 & 2.436 \\
PER_6 & 0.163 & 0.289 & $\mathbf{0 . 7 9 4}$ & 0.328 & 0.207 & 0.316 & 2.273 \\
PER_7 & 0.219 & 0.280 & $\mathbf{0 . 7 9 8}$ & 0.238 & 0.088 & 0.203 & 2.376 \\
PER_8 & 0.276 & 0.269 & $\mathbf{0 . 7 9 2}$ & 0.277 & 0.135 & 0.283 & 2.347 \\
PER_9 & 0.248 & 0.286 & $\mathbf{0 . 8 6 8}$ & 0.303 & 0.081 & 0.281 & 3.371 \\
SCO_1 & -0.005 & 0.004 & 0.296 & $\mathbf{0 . 7 7 2}$ & 0.060 & 0.375 & 1.784 \\
SCO_2 & -0.073 & -0.086 & 0.272 & $\mathbf{0 . 8 0 7}$ & 0.144 & 0.326 & 1.965 \\
SCO_3 & -0.016 & 0.053 & 0.304 & $\mathbf{0 . 7 9 1}$ & 0.151 & 0.345 & 1.787 \\
SCO_4 & 0.012 & 0.073 & 0.269 & $\mathbf{0 . 7 9 6}$ & 0.277 & 0.365 & 1.756 \\
SCO_5 & 0.014 & 0.040 & 0.291 & $\mathbf{0 . 7 9 9}$ & 0.248 & 0.381 & 1.801 \\
STR_1 & 0.329 & 0.230 & 0.155 & 0.203 & $\mathbf{0 . 8 9 5}$ & 0.201 & 2.262 \\
STR_2 & 0.206 & 0.231 & 0.151 & 0.259 & $\mathbf{0 . 8 8 2}$ & 0.193 & 2.255 \\
STR_3 & 0.299 & 0.253 & 0.105 & 0.160 & $\mathbf{0 . 8 8 1}$ & 0.218 & 2.122 \\
TIM_1 & -0.023 & 0.030 & 0.346 & 0.415 & 0.221 & $\mathbf{0 . 9 0 2}$ & 2.695 \\
TIM_2 & 0.011 & 0.098 & 0.359 & 0.412 & 0.256 & $\mathbf{0 . 9 1 0}$ & 2.711 \\
TIM_3 & 0.002 & -0.023 & 0.242 & 0.373 & 0.158 & $\mathbf{0 . 8 4 1}$ & 2.242 \\
TIM_4 & -0.022 & -0.015 & 0.204 & 0.355 & 0.117 & $\mathbf{0 . 7 9 3}$ & 1.965 \\
\hline & & & & & & & \\
\hline
\end{tabular}

with the remaining items ${ }^{2}$ which were imported into the SmartPLS programme for further analysis.

\footnotetext{
${ }^{2}$ In the analysis of principal axis factoring, it is advised to analyse the Kaiser-Meyer-Olkin (KMO) measure of sampling adequacy and Bartlett's test of sphericity. This measure (0.876) was above the suggested rule-of-thumb threshold of 0.6 , thus it indicates sufficient sample size. Additionally, the Chi-square value for Bartlett's test is large $(3,062.314)$ and significant $(p<0.001)$. This implies that the correlation matrix is not an identity matrix. Additionally, the extracted component has its eigenvalue above 1.0. To sum up, these three tests indicate it is safe to interpret the results.
} 
The second step assesses the evaluation of the convergent validity, discriminant validity, internal consistency and multicollinearity among the items of the construct. Convergent validity was assessed by examining the average variance extracted (AVE). An AVE value that is higher than 0.50 suggests a sufficient degree of convergent validity. This means that more than half of its indicators' variances were explained by the construct (Fornell \& Larcker, 1981). It was also advised that each item's outer loadings on its respective construct must be higher than other cross-loadings on other constructs. Table 6 shows that the AVE of all of the constructs was higher than the 0.50 threshold. Additionally, Table 4 also shows that all items loaded the highest on their respective construct, with a lower bound of 0.777 , confirming the convergent validity of all the constructs.

The assessment of the discriminant validity helps to ensure that all the construct measures are empirically unique, and that they represent the phenomena of interest not captured by other measures in the structural equation model (Hair et al., 2010). According to Fornell and Larcker (1981), this validity requires that the square root of the AVE for each latent variable be higher than any correlation among any pair of latent variables. Table 5 shows the satisfied requirements. Therefore, the discriminant validity was established (Chin, 1998).

Table 5: Discriminant Validity of Constructs

\begin{tabular}{lrrrrrr}
\hline & AGG & INT & PER & SCO & STR & TIM \\
\hline AGG & $\mathbf{0 . 8 6 2}$ & & & & & \\
INT & 0.420 & $\mathbf{0 . 8 3 4}$ & & & & \\
PER & 0.295 & 0.350 & $\mathbf{0 . 8 2 2}$ & & & \\
SCO & -0.015 & 0.026 & 0.360 & $\mathbf{0 . 7 9 3}$ & & \\
STR & 0.316 & 0.269 & 0.155 & 0.233 & $\mathbf{0 . 8 8 6}$ & \\
TIM & -0.008 & 0.038 & 0.348 & 0.453 & 0.231 & $\mathbf{0 . 8 6 3}$ \\
\hline
\end{tabular}

The composite reliability (CR) and Cronbach's Alpha were examined to establish internal consistency of the constructs. The CR scores and Cronbach's Alpha need to be higher than the 0.70 threshold value (Hair, Ringle, \& Sarstedt, 2011). Table 6 reveals that the internal consistency was well established.

Finally, by examining the VIF scores, multicollinearity among the construct items was assessed. Table 4 indicates that all the VIFs were 
Table 6: Cronbach's Alpha, Composite Reliability, AVE, and $\sqrt{\text { AVE }}$ of Constructs

\begin{tabular}{lcccc}
\hline & Cronbach's Alpha & Composite Reliability & AVE & $\sqrt{ }$ AVE \\
\hline AGG & 0.913 & 0.935 & 0.744 & 0.863 \\
INT & 0.782 & 0.872 & 0.696 & 0.834 \\
PER & 0.940 & 0.949 & 0.675 & 0.822 \\
SCO & 0.853 & 0.894 & 0.629 & 0.793 \\
STR & 0.863 & 0.916 & 0.785 & 0.886 \\
TIM & 0.887 & 0.921 & 0.744 & 0.863 \\
\hline
\end{tabular}

less than the threshold value of 5, thereby suggesting an absence of multicollinearity among both the measurement items (Hair et al., 2011).

\subsubsection{Estimating the Structural Model}

Following the assessment of the measurement model's validity, the next step is to estimate the structural model. Hair et al. (2011) proposed assessing the statistical significance of the parameter estimates through the bootstrapping procedure of 5,000 replacements. Before examining the paths' magnitude and strength, it is also necessary to access multicollinearity between the latent variables, the predictive validity of the parameter estimates as well as the predictive power. For this to occur, multicollinearity between the latent variables, the VIF of each latent variable needs to be less than the threshold value of 5 (Hair et al., 2011). Table 7 shows that these VIF values fulfill the criteria. Thus, multicollinearity between the latent variables was absent.

The access predictive validity of the parameter has to be examined via the Stone-Geisser Q2 value (Geisser, 1974; Stone, 1974). Tenenhaus,

Table 7: VIFs between Latent Variables

\begin{tabular}{lcccccc}
\hline Variables & AGG & INT & PER & SCO & STR & TIM \\
\hline AGG & - & - & 1.216 & - & - & - \\
INT & - & - & 1.218 & - & - & - \\
PER & - & - & - & - & - & - \\
SCO & - & - & 1.258 & - & - & - \\
STR & 1.000 & 1.000 & - & 1.000 & - & 1.000 \\
TIM & - & - & 1.259 & - & - & - \\
\hline
\end{tabular}


Vinzi, Chatelin and Lauro (2005) and Vandenbosch (1996) argued that the PLS models lacked an index. This value, thus, has to be examined in order to provide sufficient evidence of model fit. It further provides the goodness of fit statistics of structural equation models. $\mathrm{Q}^{2}$ values that are larger than zero, for a certain endogenous latent variable, indicate the path model's predictive relevance for this particular construct (Chin, 1998; Hair et al., 2011). In this study, the $\mathrm{Q}^{2}$ values of the endogenous latent variable were found to be greater than zero, thereby suggesting sufficient evidence of model fit. Table 8 shows that the $\mathrm{Q}^{2}$ values of all the endogenous latent variables were greater than zero. Thus, it is safe to conclude that the predictive validity of the parameter estimates is sufficient.

Table 8: $\mathrm{R}^{2}$ and $\mathrm{Q}^{2}$

\begin{tabular}{lcc}
\hline Variables & $\mathrm{R}^{2}$ & $\mathrm{Q}^{2}$ \\
\hline AGG & 0.100 & 0.066 \\
INT & 0.072 & 0.043 \\
PER & 0.316 & 0.193 \\
SCO & 0.054 & 0.028 \\
STR & - & - \\
TIM & 0.053 & 0.034 \\
\hline
\end{tabular}

The predictive power of the structural model was also accessed by examining the R-square values of the endogenous latent variables. It indicates the amount of these variables' variance that was explained by the exogenous latent variables (Chin, 2010). Table 8 reports the R-square value of endogenous latent variables in the model.

The last step assesses the magnitude and strength of the tested paths (see Figure 2). The results revealed that the decentralised structure was positively and significantly associated with broad scope $(\beta=0.233$, $p=0.003)$, timely $(\beta=0.231, p=0.003)$, integrated $(\beta=0.269, p<0.001)$, and aggregated $(\beta=0.316, p<0.001)$ MAS information, respectively. Thus, these results support the hypotheses of $\mathrm{H}_{1 \mathrm{a}}, \mathrm{H}_{1 \mathrm{~b}^{\prime}} \mathrm{H}_{1 \mathrm{c}}$ and $\mathrm{H}_{1 \mathrm{~d}}$. Positive and significant relationships between managerial performance and broad scope $(\beta=0.255, p<0.001)$, timely $(\beta=0.225, p=0.001)$, integrated $(\beta=0.253, p<0.001)$, aggregated $(\beta=0.194, p=0.013)$ MAS information respectively are further illustrated by the results. This outcome, therefore, supports hypotheses $\mathrm{H}_{2 a}, \mathrm{H}_{2 \mathrm{~b}}, \mathrm{H}_{2 \mathrm{c}}$ and $\mathrm{H}_{2 \mathrm{~d}}$. 


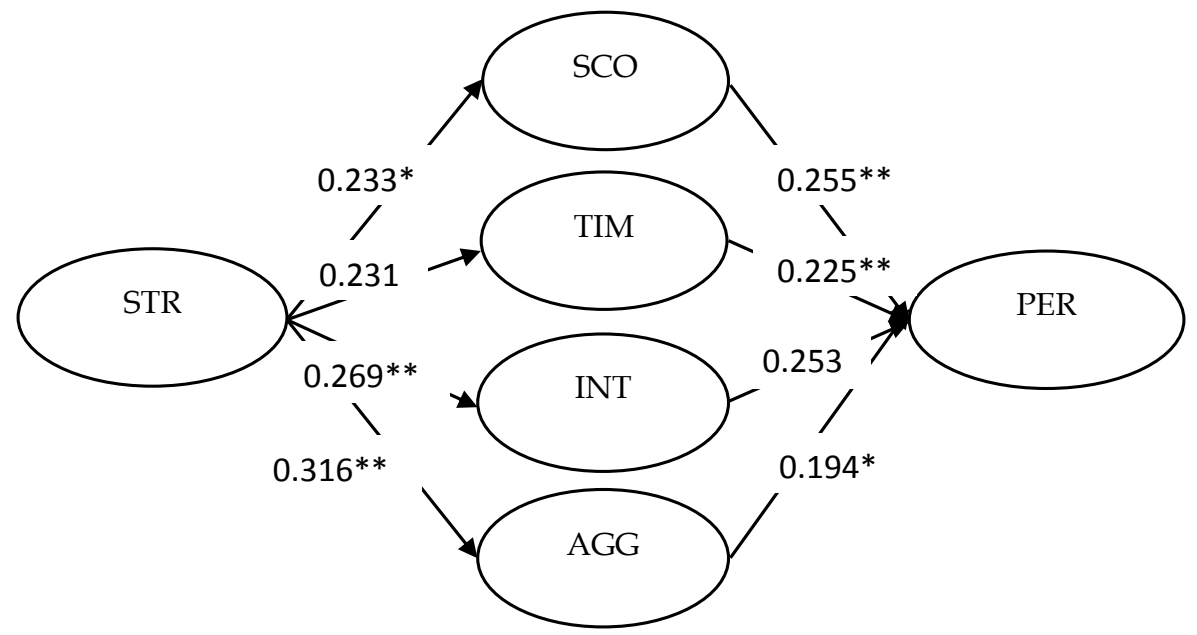

** Correlation is significant at the 0.01 level (2-tailed).

* Correlation is significant at the 0.05 level (2-tailed).

Figure 2: Results of the Structural Model

\subsubsection{Assessing the Mediating Effects}

This study assessed the mediating hypothesis by using the bootstrapping procedure which is ideal for testing mediating effects. The procedure does not require strict assumptions (e.g. distributional assumption), and is suitable for testing multiple mediations (Preacher \& Hayes, 2008). It also allows the estimation of indirect effects by assessing their significance as well as confidence intervals (CI). The SmartPLS tool was used to assess the mediating effects of MAS because it provides the results based on the bootstrapping procedure for mediating tests (Hair et al., 2017). This study relies on the procedure described by Zhao, Lynch Jr and Chen (2010) for the step-by-step analysis of the mediating effect of each characteristic of MAS. Table 9 summarises the mediating results obtained from the bootstrapping procedure of 5,000 replacements.

This study also assessed the single mediating effect of each characteristic of the MAS design on the relationship between decentralised structure and managerial performance, respectively. The mediating effects of broad scope MAS information is depicted in Table 9 which shows that decentralised structure is positively associated with this characteristic $\left(\mathrm{a}_{1}=0.233, p=0.002\right)$. The same characteristic is also positively 
Effectiveness of Management Accounting System in Public Healthcare Sector

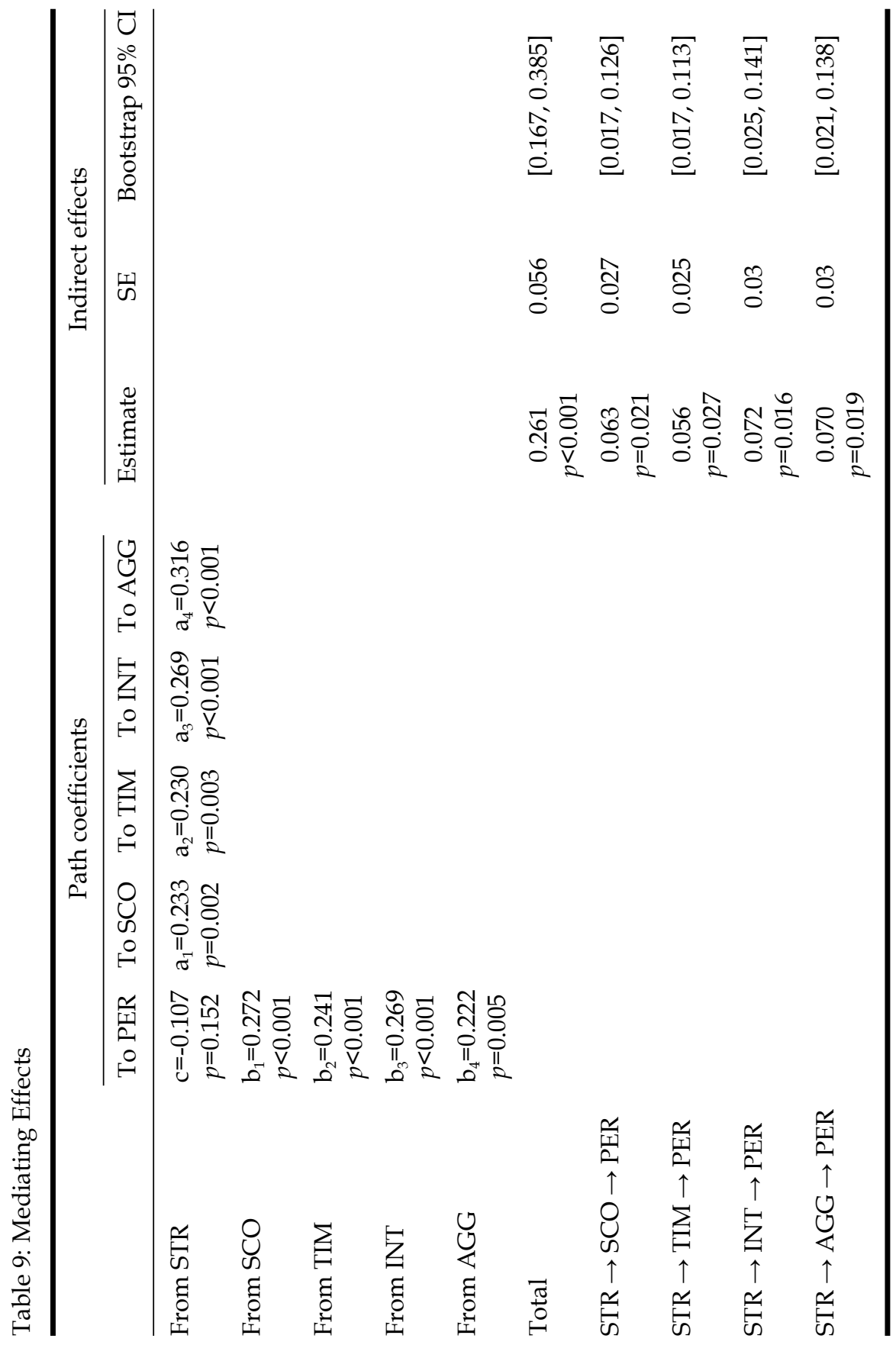


associated with managerial performance $\left(b_{1}=0.272, p<0.001\right)$. Because two paths were significant, the next step is to examine the indirect effect. The results from Table 9 indicated that indirect effect was significant $\left(a_{1} * b_{1}=0.063, p=0.021\right)$, and its CI was from the lower bound of 0.017 to the upper bound of 0.126 , which does not include zero. Therefore, it is safe to conclude that broad scope MAS information mediates the relationship between decentralised structure and managerial performance. Further to this, Table 9 also reveals that the direct path between decentralised structure and managerial performance is insignificant $(c=-0.107, p=0.152)$ when the path between path $\mathrm{a}_{1}$ and $\mathrm{a}_{2}$ was controlled. As a result, it supports the full mediating effects of broad scope MAS information.

The results shown in Table 9 also implies that the last three characteristics of MAS - timely, integrated and aggregated information, mediate the relationship between decentralised structure and managerial performance. This outcome is in line with previous analysis, thereby revealing the full mediating effects of timely, integrated and aggregated information.

Last but not least, the results also disclosed the multiple mediators of the MAS design. Specifically, the total indirect effect was noted to be significant $\left(a_{1} * b_{1}+a_{2} * b_{2}+a_{3} * b_{3}+a_{4} * b_{4}=0.261, p<0.001\right)$. Added to this outcome is that $\mathrm{CI}$ from the lower bound was 0.167 when compared to the upper bound of 0.385 , which does not include zero. Thus, these findings support multiple mediators, hence it also supports hypotheses $\mathrm{H}_{3 \mathrm{a}}, \mathrm{H}_{3 \mathrm{~b}}, \mathrm{H}_{3 \mathrm{c}}$ and $\mathrm{H}_{3 \mathrm{~d}}$.

\section{Discussions}

With respect to the link shown between decentralised structure and the MAS design, the results were observed to be in line with previous MAS studies. Chenhall and Morris (1986) found that decentralised organisations emphasised the sophisticated designs of MAS to the extent that it provided more integrated and aggregated MAS. Soobaroyen and Poorundersing (2008) indicated that organisations which followed the decentralised structure tend to design MAS which provides broad scope, timely and integrated information for decision-making. Likewise, the results of this paper revealed that there is a positive association between decentralised structure and each characteristic of MAS information such as scope, timeliness, integration and aggregation, respectively. 
In comparison to other MAS studies conducted for the healthcare sector in other countries, the results derived from the current study appear to be consistent with the study of Hammad et al. (2013), who found that decentralisation was positively associated with timely, integrated and aggregated MAS information. However, the study failed to find any significant evidence which could support the hypothesis stating that decentralisation is positively related to broad scope MAS information whereas the results of the present study supported this hypothesis. This difference in results can be explained by the unique characteristic of the Vietnamese healthcare sectors. In particular, the regulation changes and reforms had promoted decentralisation in the Vietnamese healthcare sectors. As a result, managers had more authority in the decision-making (London, 2013). In this regard, managers working in Vietnamese provincial hospitals found the MAS information relevant for legal and regulatory obligations, control contacts with external parties, and long-term planning (Pomberg et al., 2012). This outcome is consistent with broad scope MAS information, which involves external, non-financial and future-oriented information. It is further argued that broad scope MAS information was more relevant than narrow scope information, especially for situations involving decentralisations (Naranjo-Gil \& Hartmann, 2007). Consequently, there is a positive association between decentralised structure and broad scope MAS information.

The results of this study are also in line with previous research. Ghasemi et al. (2016) and Ghasemi et al. (2019) found that the three characteristics of MAS, including scope, timeliness and aggregation, could induce higher managerial performance. Soobaroyen and Poorundersing (2008) revealed that managers improved their performance by designing a sophisticated MAS which provides broad scope, timely, integrated and aggregated information for decision making. In the healthcare contexts, Hammad et al. (2013) also indicated that broad scope and timely MAS information is crucial for the enhancement of managerial performance.

In comparison to the study of Hammad et al. (2013), this study has shown a significant relationship between integrated and aggregated MAS information and managerial performance. Such an outcome was not detected by Hammad et al. (2013). There are two proper explanations for these two significant paths. Specifically, this study has revealed the significant association between aggregated MAS information and managerial performance. Thus, it is suggested that 
aggregated information is preferable in management than disaggregated ones due to information overload (Hammad et al., 2013). The latter may result in lower managerial performance. Hammad et al. (2013) admitted that less aggregated information hampered the managerial performance of hospital managers.

The results of this study also highlighted the association between integrated MAS information and managerial performance. The results can be explained as follows. Coordination between departments, specialities and functions is quite common in the healthcare contexts (Lillrank, 2012). Therefore, it is proposed that this coordination be managed adequately so as to ensure high performance in the healthcare contexts (Nyland \& Pettersen, 2004). Because integrated information emphasises the impacts of other departments' inputs, outputs and technology used on managers' department, performance may therefore be enhanced through the coordinated tasks occurring between departments. This explains the significant path between aggregated MAS information and managerial performance.

Further, the mediating effects of MAS on the relationship between decentralised structure and managerial performance has been noted in this study, to be consistent with previous studies. Ghasemi et al. (2016) showed that the three characteristics of MAS such as scope, timeliness and integration, mediated the link between competition and managerial performance. Similarly, Ghasemi et al. (2019) emphasised that these three characteristics fostered the mediating effects on the relationship between technology and managerial performance. Similarly, the current study was able to demonstrate that the four characteristics of scope, timeliness, integration and aggregation, were mediators of the association between decentralised structure and managerial performance.

\section{Conclusion, Implications, Limitations and Future Research}

The public healthcare sector of Vietnam has changed dramatically in recent years due to the series of health reforms implemented. These reforms have driven Vietnamese public healthcare organisations to behave differently from their public counterparts in other countries such as Hong Kong or Thailand (Ramesh, 2013). It is proposed that these organisations adopt MAS as a tool to improve their organisational performance (Pomberg et al., 2012). In examining the effectiveness of MAS when used by the healthcare organisations, this study argues that that one consequence of the regulation changes had resulted in 
the decentralised structure of the Vietnamese public healthcare organisations (London, 2013). Hence, this paper proposed that decentralised structure is a contextual factor driving these organisations to design more sophisticated MAS which provides broad scope, timely, integrated and aggregated information, and as a result, it led to the enhancement of managerial performance. Data collected from 165 respondents working at the Vietnamese public healthcare organisations were used to test the proposed model. The results supported all the hypotheses formulated. The results also showed the mediation effects of each characteristic of MAS on the relationship between decentralised structure and managerial performance.

In light of the findings, this study thus contributes to recent literature in three ways. First, it contributes to the literature of management accounting in Vietnam by shedding light on the use of management accounting by the public healthcare sector. Pomberg et al. (2012) had found that public hospitals were more likely to adopt management accounting against the environmental changes, and this in turn, resulted in an optimistic managerial view of the usefulness of accounting information for improvements. Nonetheless, this study does not answer which types of accounting information can crucially influence improvements. Fung (2012) had urged that future studies examine whether or not MAS information could lead to high managerial performance. By using the contingency theory, this study had disclosed that each characteristic of MAS information contributes to managerial performance.

Gerdin and Greve (2004) had suggested that frameworks be formulated for the mediating model in contingency research. Past studies examining the mediating effects had failed to take into account this suggestion because they did not provide any form of fits between contextual factors and the effectiveness of MAS (see Ghasemi et al., 2016; Ghasemi et al., 2019; Soobaroyen \& Poorundersing, 2008). As such, it leads to the methodological limitations in contingency research. By taking into account the suggestions, this paper overcomes previous studies' limitation by using the contingency approach in the cartesian form of fit to explain the mediation effects of MAS design on the link between decentralised structure and managerial performance. By doing so, this study contributes to the growing body of accounting evidence on the effects of cartesian-contingency-mediation in contingency research (see Albalaki, Abdullah \& Kamardin, 2019; Cadez \& Guilding, 2008; Elgharbawy \& Abdel-Kader, 2013; Kennedy \& Widener, 2008). 
This study also contributes to the healthcare literature by offering additional evidence on the crucial role of accounting in healthcare contexts. Particularly, previous studies had indicated that accounting data can be used in hospital for improving efficiency and effectiveness (Abernethy \& Lillis, 2001), enhancing competitive ability (Krishnan, 2005), and supporting process orientations (Kastberg \& Siverbo, 2013). In the same vein, the results of this study revealed that MAS information fostered managerial performance. In this way, the results of this study enriched the healthcare literature on the use of accounting data for improvement.

This study offers some useful implications for practitioners. Mainly, practitioners should take into account the crucial role of healthcare organisations' structure when examining the design of MAS. When the structure is more decentralised, MAS should be designed sophisticatedly. It allows the provision of broad scope, timely, integrated and aggregated information for decision-making. This consideration is quite important because the more sophisticated design requires organisations to collect and process information, which results in high cost.

Practitioners should also focus on the characteristics of MAS information. Although a piece of empirical evidence from Pomberg et al. (2012) had indicated that MAS information was useful to some degree, it did not precisely state the characteristics which enhanced managerial performance. The current study had adopted the framework of Chenhall and Morris (1986) to examine the impact of each characteristic of MAS information on managerial performance. Hence, practitioners can use this framework as indicators to design MAS so as to understand which characteristic can foster a positive effect on managerial performance dramatically.

The results of this study are, however, subjected to some caveats. First, data were collected by using a questionnaire. Further, only managers working at healthcare organisations in Can Tho city were recruited. Based on this, the results cannot be generalised to the entire country of Vietnam. Second, this study did not engage a pilot test to evaluate the questionnaire, hence, there could be some bias in the findings due to the process of translation. Nonetheless, this bias is not a major concern because the questionnaire had been carefully examined by chief accountants who have experience in public healthcare sectors. Third, using self-rated scales to measure managerial performance may generate higher mean values, thereby causing higher leniency error and a restricted range causing lower variability error in the observed scale 
(Prien \& Liske, 1962; Thornton, 1968). Thus, these may have an impact on the results of this study.

Despite these limitations, this study has created an avenue for future research. Future studies should extend on the current study by including healthcare organisations at the central levels. Doing so allows for more insights to be gained about the design of MAS in these organisations because (Pomberg et al., 2012) had found that provincial managers perceived the usefulness of MAS information differently from central managers. Moreover, the mediating effects of MAS on the link between performance and other contextual variables in healthcare contexts can be further examined. Finally, future studies may consider investigating the impact of other contextual factors that had resulted from the regulation change affecting the effectiveness of MAS. A fruitful avenue is to examine the regulatory influence and obligation on MAS.

\section{References}

Abernethy, M.A., \& Lillis, A.M. (2001). Interdependencies in organization design: A test in hospitals. Journal of Management Accounting Research, 13(1), 107-129. http://dx.doi.org/10.2308/jmar.2001.13.1.107

Agbejule, A. (2005). The relationship between management accounting systems and perceived environmental uncertainty on managerial performance: A research note. Accounting and Business Research, 35(4), 295-305. http:// dx.doi.org/10.1080/00014788.2005.9729996

Albalaki, F.M.M., Abdullah, Z., \& Kamardin, H. (2019). The influence of external contingency factors and activity-based costing implementation on organizational performance. Jurnal Pengurusan (UKM Journal of Management), 55.

Ali, F., Rasoolimanesh, S.M., Sarstedt, M., Ringle, C.M., \& Ryu, K. (2018). An assessment of the use of partial least squares structural equation modeling (PLS-SEM) in hospitality research. International Journal of Contemporary Hospitality Management, 30(1), 514-538. http://dx.doi.org/10.1108/IJCHM10-2016-0568

Cadez, S., \& Guilding, C. (2008). An exploratory investigation of an integrated contingency model of strategic management accounting. Accounting, Organizations and Society, 33(7-8), 836-863. http://dx.doi.org/10.1016/j. aos.2008.01.003

Campanale, C., Cinquini, L., \& Tenucci, A. (2014). Time-driven activity-based costing to improve transparency and decision making in healthcare: A case study. Qualitative Research in Accounting \& Management, 11(2), 165-186. http://dx.doi.org/10.1108/QRAM-04-2014-0036

Cassel, C., Hackl, P., \& Westlund, A.H. (1999). Robustness of partial leastsquares method for estimating latent variable quality structures. Journal of Applied Statistics, 26(4), 435-446. http:/ / dx.doi.org/10.1080/02664769922322 
Chenhall, R.H. (2003). Management control systems design within its organizational context: Findings from contingency-based research and directions for the future. Accounting, Organizations and Society, 28(2-3), 127-168. http://dx.doi.org/10.1016/S0361-3682(01)00027-7

Chenhall, R.H., \& Morris, D. (1986). The impact of structure, environment, and interdependence on the perceived usefulness of management accounting systems. Accounting Review, 61(1), 16-35.

Chia, Y.M. (1995). Decentralization, management accounting system (MAS) information characteristics and their interaction effects on managerial performance: A Singapore study. Journal of Business Finance $\mathcal{E}$ Accounting, 22(6), 811-830. http:/ /dx.doi.org/10.1111/j.1468-5957.1995.tb00390.x

Chin, W.W. (1998). The partial least squares approach to structural equation modeling. Modern Methods for Business Research, 295(2), 295-336.

Chin, W.W. (2010). How to write up and report PLS analyses. In Vinzi V. Esposito, W. Chin, J. Henseler, \& H. Wang (Eds.), Handbook of partial least squares. Springer Handbooks of Computational Statistics (pp. 655-690). Berlin, Heidelberg: Springer. http://dx.doi.org/10.1007/978-3-540-32827-8_29

Chong, V.K. (1998). Testing the contingency «fit» between management accounting systems and managerial performance: A research note on the moderating role of tolerance for ambiguity. The British Accounting Review, 30(4), 331-342. http:/ / dx.doi.org/10.1006/bare.1998.0073

Chong, V.K., \& Chong, K.M. (1997). Strategic choices, environmental uncertainty and SBU performance: A note on the intervening role of management accounting systems. Accounting and Business Research, 27(4), 268-276. http:/ / dx.doi.org/10.1080/00014788.1997.9729553

Chong, V.K., \& Eggleton, I.R. (2003). The decision-facilitating role of management accounting systems on managerial performance: The influence of locus of control and task uncertainty. Advances in Accounting, 20, 165-197. http:/ / dx.doi.org/10.1016/S0882-6110(03)20008-0

Cushing, B.E., \& Romney, M.B. (1994). Accounting information systems. Reading, MA: Addison-Wesley Longman Publishing Co., Inc.

Dalton, D.R., Todor, W.D., Spendolini, M.J., Fielding, G.J., \& Porter, L.W. (1980). Organization structure and performance: A critical review. Academy of Management Review, 5(1), 49-64. http://dx.doi.org/10.5465/amr.1980. 4288881

Ditzel, E., Štrach, P., \& Pirozek, P. (2006). An inquiry into good hospital governance: A New Zealand-Czech comparison. Health Research Policy and Systems, 4(1), 2. http:/ / dx.doi.org/10.1186/1478-4505-4-2

Elgharbawy, A., \& Abdel-Kader, M. (2013). Enterprise governance and valuebased management: A theoretical contingency framework. Journal of Management $\mathcal{E}$ Governance, 17(1), 99-129. http://dx.doi.org/10.1007/s10997012-9220-y

Emmanuel, C., Otley, D., \& Merchant, K. (1990). Accounting for management control. In C. Emmanuel, D. Otley, \& K. Merchant, Accounting for 
management control (pp. 357-384). Boston, MA: Springer. http://dx.doi. org/10.1007/978-1-4899-6952-1_13

Etemadi, H., Dilami, Z.D., Bazaz, M.S., \& Parameswaran, R. (2009). Culture, management accounting and managerial performance: Focus Iran. Advances in Accounting, 25(2), 216-225. http://dx.doi.org/10.1016/j.adiac. 2009.08.005

Fabrigar, L.R., Wegener, D.T., MacCallum, R.C., \& Strahan, E.J. (1999). Evaluating the use of exploratory factor analysis in psychological research. Psychological Methods, 4(3), 272-299. https://doi.org/10.1037/1082-989X.4.3.272

Fornell, C., \& Larcker, D.F. (1981). Evaluating structural equation models with unobservable variables and measurement error. Journal of Marketing Research, 18(1), 39-50. http://dx.doi.org/10.1177\%2F002224378101800104

Fung, S.Y.K. (2012). Discussion of "Management accounting information systems in a developing country". Asia-Pacific Journal of Accounting $\mathcal{E}$ Economics, 19(1), 115-118. http://dx.doi.org/10.1080/16081625.2012.668061

Geisser, S. (1974). A predictive approach to the random effect model. Biometrika, 61(1), 101-107. http://dx.doi.org/10.1093/biomet/61.1.101

Gerdin, J. (2005). Management accounting system design in manufacturing departments: An empirical investigation using a multiple contingencies approach. Accounting, Organizations and Society, 30(2), 99-126. http:// dx.doi.org/10.1016/j.aos.2003.11.003

Gerdin, J., \& Greve, J. (2004). Forms of contingency fit in management accounting research-A critical review. Accounting, Organizations and Society, 29(3-4), 303-326. http://dx.doi.org/10.1016/S0361-3682(02)00096-X

Ghasemi, R., Mohamad, N.A., Karami, M., Bajuri, N.H., \& Asgharizade, E. (2016). The mediating effect of management accounting system on the relationship between competition and managerial performance. International Journal of Accounting and Information Management, 24(3), 272-295. http:/ / dx.doi.org/10.1108/IJAIM-05-2015-0030

Ghasemi, R., Habibi, H.R., Ghasemlo, M., \& Karami, M. (2019). The effectiveness of management accounting systems: Evidence from financial organizations in Iran. Journal of Accounting in Emerging Economies, 9(2), 182-207. http:// dx.doi.org/10.1108/JAEE-02-2017-0013

Gordon, L.A., \& Miller, D. (1976). A contingency framework for the design of accounting information systems. In L.A. Gordon \& D. Miller, Readings in accounting for management control (pp. 569-585). Boston, MA: Springer. http://dx.doi.org/10.1007/978-1-4899-7138-8_26

Gul, F.A., \& Chia, Y.M. (1994). The effects of management accounting systems, perceived environmental uncertainty and decentralization on managerial performance: A test of three-way interaction. Accounting, Organizations and Society, 19(4-5), 413-426. http:/ /dx.doi.org/10.1016/0361-3682(94)90005-1

Hair, J.F., Anderson, R.E., Babin, B.J., \& Black, W.C. (2010). Multivariate data analysis: A global perspective (Vol. 7). Upper Saddle River, NJ: Pearson. 
Hair, J.F., Hult, G.T.M., Ringle, C.M., Sarstedt, M., \& Thiele, K.O. (2017). Mirror, mirror on the wall: A comparative evaluation of composite-based structural equation modeling methods. Journal of the Academy of Marketing Science, 45(5), 616-632. http://dx.doi.org/10.1007/s11747-017-0517-x

Hair, J.F., Ringle, C.M., \& Sarstedt, M. (2011). PLS-SEM: Indeed a silver bullet. Journal of Marketing Theory and Practice, 19(2), 139-152. http://dx.doi.org/ 10.2753/MTP1069-6679190202

Hammad, S.A., Jusoh, R., \& Ghozali, I. (2013). Decentralization, perceived environmental uncertainty, managerial performance and management accounting system information in Egyptian hospitals. International Journal of Accounting and Information Management, 21(4), 314-330. http://dx.doi. org/10.1108/IJAIM-02-2012-0005

Hammad, S.A., Jusoh, R., \& Oon, E.Y.N. (2010). Management accounting system for hospitals: A research framework. Industrial Management $\mathcal{E}$ Data Systems, 110(5), 762-784. http:// dx.doi.org/10.1108/02635571011044777

Hill, N.T. (2000). Adoption of costing systems in US hospitals: An event history analysis 1980-1990. Journal of Accounting and Public Policy, 19(1), 41-71. http://dx.doi.org/10.1016/S0278-4254(99)00013-7

Ismail, K., \& Isa, C.R. (2011). The role of management accounting systems in advanced manufacturing environment. Australian Journal of Basic and Applied Sciences, 5(9), 2196-2209.

Kastberg, G., \& Siverbo, S. (2013). The design and use of management accounting systems in process oriented health care - an explorative study. Financial Accountability \& Management, 29(3), 246-270. http://dx.doi.org/ 10.1111/faam.12014

Kennedy, F.A., \& Widener, S.K. (2008). A control framework: Insights from evidence on lean accounting. Management Accounting Research, 19(4), 301323. http://dx.doi.org/10.1016/j.mar.2008.01.001

Krishnan, R. (2005). The effect of changes in regulation and competition on firms' demand for accounting information. The Accounting Review, 80(1), 269-287. http://dx.doi.org/10.2308/accr.2005.80.1.269

Le, D.C., Kubo, T., Fujino, Y., Pham, T.M., \& Matsuda, S. (2010). Health care system in Vietnam: Current situation and challenges. Asian Pacific Journal of Disease Management, 4(2), 23-30.

Lillrank, P. (2012). Integration and coordination in healthcare: An operations management view. Journal of Integrated Care, 20(1) 6-12. http://dx.doi. org/10.1108/14769011211202247

Lindell, M.K., \& Whitney, D.J. (2001). Accounting for common method variance in cross-sectional research designs. Journal of Applied Psychology, 86(1), 114121. https://doi.org/10.1037/0021-9010.86.1.114

London, J.D. (2013). The promises and perils of hospital autonomy: Reform by decree in Viet Nam. Social Science \& Medicine, 96, 232-240. http://dx.doi. org/10.1016/j.socscimed.2013.07.009 
Macinati, M.S., \& Anessi-Pessina, E. (2014). Management accounting use and financial performance in public health-care organisations: Evidence from the Italian National Health Service. Health Policy, 117(1), 98-111. http:// dx.doi.org/10.1016/j.healthpol.2014.03.011

Macinati, M.S., \& Rizzo, M.G. (2014). Budget goal commitment, clinical managers' use of budget information and performance. Health Policy, 117(2), 228-238. http:/ / dx.doi.org/10.1016/j.healthpol.2014.05.003

Mahoney, T.A. (1963). Development of managerial performance: A research approach. Cicinnati, MN: South-western Publishing Company.

Mak, Y.T. (1989). Contingency fit, internal consistency and financial performance. Journal of Business Finance $\mathcal{E}$ Accounting, 16(2), 273-300. http:// dx.doi.org/10.1111/j.1468-5957.1989.tb00019.x

Mia, L., \& Chenhall, R.H. (1994). The usefulness of management accounting systems, functional differentiation and managerial effectiveness. Accounting, Organizations and Society, 19(1), 1-13. http://dx.doi.org/10.1016/03613682(94)90010-8

Miah, N.Z., \& Mia, L. (1996). Decentralization, accounting controls and performance of government organizations: A New Zealand empirical study. Financial Accountability \& Management, 12(3), 173-190. http://dx.doi. org/10.1111/j.1468-0408.1996.tb00421.x

Naranjo-Gil, D., \& Hartmann, F. (2007). Management accounting systems, top management team heterogeneity and strategic change. Accounting, Organizations and Society, 32(7-8), 735-756. http://dx.doi.org/10.1016/j. aos.2006.08.003

Nguyen, T.T., Mia, L., Winata, L., \& Chong, V.K. (2017). Effect of transformational-leadership style and management control system on managerial performance. Journal of Business Research, 70, 202-213. http:// dx.doi.org/10.1016/j.jbusres.2016.08.018

Nyland, K., \& Pettersen, I.J. (2004). The control gap: The role of budgets, accounting information and (non-) decisions in hospital settings. Financial Accountability $\mathcal{E}$ Management, 20(1), 77-102. http://dx.doi.org/10.1111/ j.1468-0408.2004.00187.x

Pizzini, M.J. (2006). The relation between cost-system design, managers' evaluations of the relevance and usefulness of cost data, and financial performance: An empirical study of U.S. hospitals. Accounting, Organizations and Society, 31(2), 179-210. http://dx.doi.org/10.1016/j.aos.2004.11.001

Podsakoff, P.M., \& Organ, D.W. (1986). Self-reports in organizational research: Problems and prospects. Journal of Management, 12(4), 531-544. http:// dx.doi.org/10.1177\%2F014920638601200408

Pomberg, M., Pourjalali, H., Daniel, S., \& Kimbro, M.B. (2012). Management accounting information systems: A case of a developing country: Vietnam. Asia-Pacific Journal of Accounting E Economics, 19(1), 100-114. http:/ / dx.doi. org/10.1080/16081625.2012.668060 
Preacher, K.J., \& Hayes, A.F. (2008). Asymptotic and resampling strategies for assessing and comparing indirect effects in multiple mediator models. Behavior Research Methods, 40(3), 879-891. http://dx.doi.org/10.3758/BRM. 40.3.879

Prien, E.P., \& Liske, R.E. (1962). Assessments of higher-level personnel: III. Rating criteria: A comparative analysis of supervisor ratings and incumbent self-ratings of job performance. Personnel Psychology, 15(2), 187194. http://dx.doi.org/10.1111/j.1744-6570.1962.tb01860.x

Radford, A., Pink, G., Ricketts, T., \& Spade, J. (2007). A comparative performance scorecard for federally funded community health centers in North Carolina. Journal of Healthcare Management, 52(1), 20-31.

Ramesh, M. (2013). Health care reform in Vietnam: Chasing shadows. Journal of Contemporary Asia, 43(3), 399-412. http://dx.doi.org/10.1080/00472336.201 3.763497

Ramsey, R.H. (1994). Activity-based costing for hospitals. Journal of Healthcare Management, 39(3), 385-396.

Rook, D.W., \& Fisher, R.J. (1995). Normative influences on impulsive buying behavior. Journal of Consumer Research, 22(3), 305-313. http://dx.doi.org/ $10.1086 / 209452$

Soobaroyen, T., \& Poorundersing, B. (2008). The effectiveness of management accounting systems. Managerial Auditing Journal, 23(2), 187-219. http:// dx.doi.org/10.1108/02686900810839866

Stadhouders, N., Koolman, X., Tanke, M., Maarse, H., \& Jeurissen, P. (2016). Policy options to contain healthcare costs: A review and classification. Health Policy, 120(5), 486-494. http:/ / dx.doi.org/10.1016/j.healthpol.2016.03.007

Stone, M. (1974). Cross-validatory choice and assessment of statistical predictions. Journal of the Royal Statistical Society: Series B (Methodological), 36(2), 111-133. http://dx.doi.org/10.1111/j.2517-6161.1974.tb00994.x

Tenenhaus, M., Vinzi, V.E., Chatelin, Y.M., \& Lauro, C. (2005). PLS path modeling. Computational Statistics \& Data Analysis, 48(1), 159-205. http:// dx.doi.org/10.1016/j.csda.2004.03.005

Thompson, J.D. (1967). Organizations in action: Social science bases of administrative theory. New York, NY: McGraw-Hill.

Thornton, G.C. (1968). The relationship between supervisory- and self-appraisals of executive performance. Personnel Psychology, 21(4), 441-455. http:// dx.doi.org/10.1111/j.1744-6570.1968.tb02044.x

Tsui, J.S. (2001). The impact of culture on the relationship between budgetary participation, management accounting systems, and managerial performance: An analysis of Chinese and Western managers. The International Journal of Accounting, 36(2), 125-146. http://dx.doi.org/10.1016/S00207063(01)00101-7

Van den Ven, A. (1976). A framework for organizational assessment. Academy of Management Review, 1(1), 64-78. 
Vandenbosch, M.B. (1996). Confirmatory compositional approaches to the development of product spaces. European Journal of Marketing, 30(3), 23-46. http://dx.doi.org/10.1108/03090569610107418

Westra, D., Angeli, F., Carree, M., \& Ruwaard, D. (2017). Understanding competition between healthcare providers: Introducing an intermediary interorganizational perspective. Health Policy, 121(2), 149-157. http://dx.doi. org/10.1016/j.healthpol.2016.11.018

Zhao, X., Lynch Jr, J.G., \& Chen, Q. (2010). Reconsidering Baron and Kenny: Myths and truths about mediation analysis. Journal of Consumer Research, 37(2), 197-206. http:/ /dx.doi.org/10.1086/651257 
